\title{
3, 4-Dihydroxyphenylacetic Acid (DOPAC) Impairs $\alpha$-Synuclein Interaction with Lipids
}

\author{
Wenbo Zhou ${ }^{1}$, Chunmei Long ${ }^{1}$, Anthony L. Fink ${ }^{1}$ and Vladimir N. Uversky ${ }^{1-3, *}$ \\ ${ }^{I}$ Department of Chemistry and Biochemistry, University of California, Santa Cruz, CA 95064, USA \\ ${ }^{2}$ Institute for Intrinsically Disordered Protein Research, Department of Biochemistry and Molecular Biology, Center for \\ Computational Biology and Bioinformatics, Indiana University School of Medicine, Indianapolis, IN 46202-2111, USA \\ ${ }^{3}$ Institute for Biological Instrumentation, Russian Academy of Sciences, 142290 Pushchino, Moscow Region, Russia
}

\begin{abstract}
Synuclein ( $\alpha$-Syn) is a small intrinsically disordered presynaptic protein known to form insoluble filamentous inclusions in Parkinson's disease (PD) and other neurodegenerative disorders. Various catecholamines can inhibit the $\alpha$-Syn fibrillation in vitro. Recently, non-covalent binding of DOPAC (3,4-dihydroxyphenylacetic acid), a normal product of the dopamine metabolism, was shown to inhibit the fibrillation of $\alpha$-Syn due to the DOPAC-induced stabilization of the normally transient oligomers thus preventing them from subsequent fibril formation (Zhou, et al. J. Mol. Biol. 2009, 388 (3), 597-610). We are showing here that the interaction of DOPAC with $\alpha$-Syn decreases the binding affinity of $\alpha$ Syn to lipids, suggesting that DOPAC might lead to the gain-of-toxicity of $\alpha$-Syn aggregates and loss-of-function of $\alpha$ Syn, both of which could be related to progression of PD.
\end{abstract}

Keywords: $\alpha$-Synuclein, Parkinson's disease, aggregation, oligomerization, intrinsically disordered protein.

\section{INTRODUCTION}

$\alpha$-Synuclein $(\alpha$-Syn), a 140 -residue presynaptic protein of unknown function, is one of the major components of Lewy bodies and Lewy neurites [1-3], proteinaceous fibrillar inclusions found in brains of patients with Parkinson's disease (PD) and several other neurodegenerative diseases, collectively know as synucleinopathies [4-15]. In vitro, $\alpha-$ Syn assembles into filaments after incubation under physiological conditions, with morphologies similar to those of filaments extracted from diseased brain [16-19].

Far-UV CD, FTIR and NMR spectroscopy combined with several hydrodynamic techniques showed that $\alpha$-Syn does not have ordered tertiary or secondary structure and is extended in vitro; i.e., behaves as a typical intrinsically disordered protein [4, 13, 14, 20-25]. Seven 11-amino-acid imperfect repeats with a conservative hexameric motif KTKEGV are located in the N-terminal half of $\alpha$-Syn [26, 27]. These repeats resemble the lipid binding domains of class $\mathrm{A}_{2}$ apolipoproteins [26]. On binding to negatively charged phospholipids, $\alpha$-Syn becomes $\alpha$-helical [28-32].

Although the normal function of $\alpha$-Syn is still unknown, it is believed that this protein is involved in regulation of dopamine neurotransmission affecting the vesicular dopamine storage and trafficking [33-37]. Interestingly, dopamine and related compounds that have vicinal dihydroxy

\footnotetext{
*Address correspondence to this author at the Institute for Intrinsically Disordered Protein Research, Center for Computational Biology \& Bioinformatics, Department of Biochemistry and Molecular Biology, Indiana University Schools of Medicine and Informatics, $410 \mathrm{~W}$. 10th Street, HS 5009, Indianapolis, IN 46202, USA; Tel: 317-278-6448; Fax: 317-2789217; E-mail: vuversky@iupui.edu

"Prof. Anthony L. Fink has passed away on March 2, 2008
}

groups were shown to inhibit the fibrillation of $\alpha$-Syn in vitro [38-43]. The oxidized dopamine quinone binds to $\alpha$ Syn, inhibits its fibrillation and stabilizes $\alpha$-Syn oligomers [38]. Furthermore, the neurotoxicity of $\alpha$-Syn is dopaminedependent [44].

We have shown that DOPAC (3, 4-dihydroxyphenyl acetic acid, a normal product of the metabolism of dopamine), similar to dopamine, can bind to $\alpha$-Syn, stabilize its oligomers and prevents this protein from fibrillation [45]. Here we further show that DOPAC binding to $\alpha$-Syn decreases its interaction with lipids, indicating potential loss of $\alpha$-Syn function due to the DOPAC binding.

\section{MATERIALS AND METHODS}

\section{Materials}

Recombinant human $\alpha$-Syn was expressed in Escherichia coli and purified as described previously [46]. Lyophilized protein was freshly prepared before use by dissolving protein in $2 \mathrm{mM}$ phosphate buffer at $\mathrm{pH} 7.4$ and centrifuged at 95,000 rpm with a Beckmann arifuge. 3,4dihydroxyphenylacetic acid (DOPAC); 1,2-dipalmitoyl-snglycero-3-phosphate (PA) and 1,2-dipalmitoyl-sn-glycero-3phosphocholine (PC) were obtained from Aldrich. All other chemicals were of analytical grade and were purchased from the Fisher Chemicals or EM Science.

\section{$\alpha-S y n$ Fibril and Oligomers Formation}

$70 \mu \mathrm{M} \alpha$-Syn, with or without $100 \mu \mathrm{M}$ DOPAC, was incubated in $100 \mathrm{mM} \mathrm{NaCl}$ and $20 \mathrm{mM}$ phosphate buffer $(\mathrm{pH}$ 7.4) with constant stirring with a mini-stir bar. Under this condition, $\alpha$-Syn can form amyloid fibril with a lag time of $\sim 20$ hours. Normally, oligomeric $\alpha$-Syn accumulate during 
the first $\sim 20$ hours and amyloid fibrils show up after $\sim 20$ hours.

\section{Preparation of Small Unilamellar Vesicles}

Sonicated SUVs of PA/PC (molar ratio 1:1) was prepared as described previously [28]. $\alpha$-Syn was added to solutions of the vesicles immediately before circular dichroism measurements.

\section{Far-UV CD Measurements}

$70 \mu \mathrm{M} \alpha$-Syn, with or without $100 \mu \mathrm{M}$ DOPAC, was incubated in $100 \mathrm{mM} \mathrm{NaCl}$ and $20 \mathrm{mM}$ phosphate buffer $(\mathrm{pH}$ 7.4) without agitation for two days. For lipid binding assay, fresh small unilamellar vesicles made from 1:1 PA/PC was added to the above solution for Far-UV CD measurements

Far-UV CD spectra were collected with an Aviv 60DS spectrpolarimeter at $1-\mathrm{nm}$ intervals, $1.5 \mathrm{~nm}$ bandwidth and averaging time of 1.0 second. Measurements were performed in a $0.01 \mathrm{~cm}$ cell at room temperature over the range 190$250 \mathrm{~nm}$. Five scans were taken and the data were averaged.

\section{Size-Exclusion HPLC Measurements}

Aliquots of solutions were removed during incubation and centrifuged for $20 \mathrm{~min}$ at $14000 \mathrm{rpm}$ to remove any insoluble materials before running gel-filtration chromatography. $15 \mu \mathrm{L}$ of incubated solutions were injected on a TSKGEL G2000SW $_{\mathrm{XL}}$ size-exclusion column $(7.8 \mathrm{~mm}$ ID $\times 30$ $\mathrm{cm}$ ) at a flow rate of $0.5 \mathrm{~mL} / \mathrm{min}$ in $10 \mathrm{mM}$ phosphate buffer $\left(\mathrm{pH} 7.2\right.$ ) and $100 \mathrm{mM} \mathrm{Na}_{2} \mathrm{SO}_{4}$. HPLC was performed using a Waters 2695 separations module with a Waters 996 Photodiode Array detector, and data were collected and analyzed by Millennium software. Absorbance of the eluant was monitored over the wavelength range from 220 to $450 \mathrm{~nm}$ with bandwidth of $1.2 \mathrm{~nm}$.

\section{ATR-FTIR Measurements}

ATR-FTIR data were collected on a Thermo Nexus 670 FTIR spectrometer. The hydrated thin films were prepared and analyzed as described previously [47]. Typically, hydrated thin film samples were prepared by drying $30 \mu 1$ of $1 \mathrm{mg} / \mathrm{ml} \alpha$-Syn solution on a Ge crystal with dry $\mathrm{N}_{2}$. The IR spectra were collected, followed by Fourier transformation using the spectrum of the clean crystal as a background. Data were analyzed with GRAMS32 (Galactic Industries $\mathrm{Co}$ ). Final FTIR spectra were area normalized.

\section{Atomic Force Microscopy Measurements}

AFM images were collected with a PicoScan LE system (Molecular Imaging, Phoenix, AZ) equipped with Acoustic AC mode (Tapping mode) for ex-situ experiment. Triangular cantilevers with $160 \mathrm{kHz}$ resonance frequency and $2 \mathrm{~N} / \mathrm{m}$ spring constant, a V-shaped cantilever NSC16/AIBS (MikroMasch), were used in Tapping mode imaging. The imaging was carried out at a scan rate of 1 line/s with 512 data points per line, at a drive current of $10 \pm 4 \AA$. Aliquots of 10 $\mu \mathrm{l}$ of sample containing $100 \mathrm{mM} \mathrm{NaCl}$ were placed on a freshly cleaved mica substrate. After incubation at least 60 min, the substrate was rinsed with water several times to remove salt and loosely bound protein and dried with highpurity Nitrogen.
Heights ranging from 0.1 to $100 \mathrm{~nm}$ were estimated by section analysis, and lateral sizes were calibrated with standard calibration grid. At least four regions of the mica surface were examined to verify that similar structures existed through the sample. No filter treatment was used to modify the images. SPIP 4.0 (Image Metrology) was used to analyze the height, area and volume distribution of the $\alpha$-Syn aggregations.

\section{RESULTS}

\section{Instable Oligomers Are Transiently Formed During the $\alpha$-Syn Fibrillation}

Earlier we also established that the incubation of $\alpha$-Syn alone or with DOPAC was accompanied by the formation of oligomeric species [45]. When $\alpha$-Syn was incubated with agitation alone, these highly soluble oligomers accumulated during the first 20 hours (unlike fibrils, such oligomers were not pelletable by the centrifugation). Fig. 1A represents a series of AFM images collected at the different reaction times and clearly illustrates the formation of these transient oligomers. However, the SEC HPLC analysis of the $\alpha$-Syn solution incubated in the absence of DOPAC for different time intervals revealed the existence of only one peak, which corresponded to the monomeric protein (Fig. 1B). No peaks corresponding to oligomers were observed, indicating that the oligomers were relatively unstable and dissociated during the SEC experiments. The area of the monomer peak remained relatively constant for the first 20 hours and then decreased. These data agree well with the results of ThT assays which indicated that stable insoluble fibrils were formed after 20 hours (lag time) [45], suggesting that the oligomers were formed before fibrils. These oligomers dissociated to monomer on the SEC HPLC column due to the strong dilution. All these data indicated that the $\alpha$-Syn oligomers formed during fibrillation are "transient" and either form stable fibrils or dissociate to monomers being diluted [45].

\section{DOPAC Stabilizes Transient Oligomers}

It was shown that DOPAC binds to $\alpha$-Syn and inhibits its fibrillation [45]. In agreement with these earlier observations, Fig. 2A shows AFM images measured after the prolonged incubation of $\alpha$-Syn with DOPAC. This figure clearly shows that large oligomers were formed, but no fibrils were observed in the time course of $\alpha$-Syn incubation in the presence of DOPAC. Comparison AFM images in Figs. 1A and 2A shows that the heights of the oligomers formed in the presence of DOPAC were comparable with those obtained by incubating $\alpha$-Syn alone. Since no fibrils was found even after the prolonged incubation of $\alpha$-Syn with DOPAC and only oligomers were observed, the oligomers seemed to be "stabilized" by DOPAC and cannot form fibrils.

SEC HPLC data showed that $\alpha$-Syn incubated in the presence of DOPAC was mostly monomeric, although some oligomers were also formed (Fig. 2B). The height of the chromatographic peak increased gradually during incubation, indicating the DOPAC binding to $\alpha$-Syn. Furthermore, Fig. 2B shows that the peak of monomeric $\alpha$-Syn shifted gradually to the right, indicating that the hydrodynamic dimensions of $\alpha$-Syn monomer decreased slightly after the 

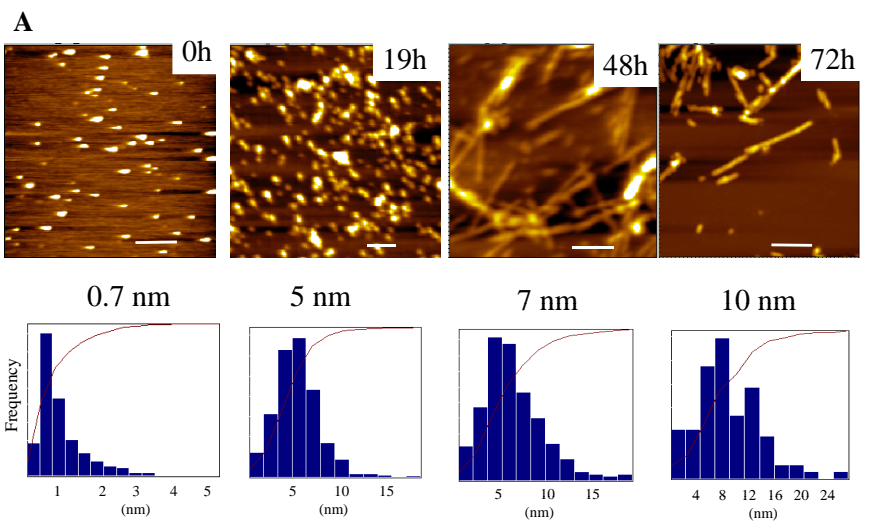

$7 \mathrm{~nm}$

$10 \mathrm{~nm}$
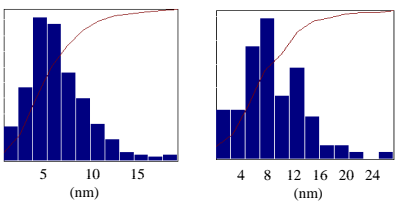

B

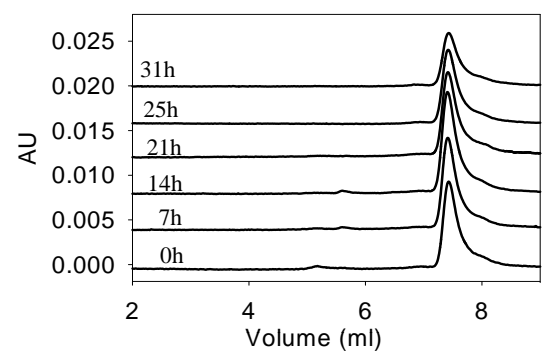

Fig. (1). (A). Time course of oligomerization and fibrillation of $\alpha$-Syn $(70 \mu \mathrm{M})$ incubated without DOPAC in $20 \mathrm{mM}$ pH $7.4 \mathrm{phosphate}$ buffer and $100 \mathrm{mM} \mathrm{NaCl}$ at $37^{\circ} \mathrm{C}$ as detected by AFM imaging. Scale bar is $200 \mathrm{~nm}$. The lower panels show the heights distribution and average heights are shown above the panels.

(B). Time course of changes in SEC HPLC profile of $\alpha-\operatorname{Syn}(70 \mu \mathrm{M})$ incubated alone at $\mathrm{pH} 7.4,37^{\circ} \mathrm{C}$ with agitation.
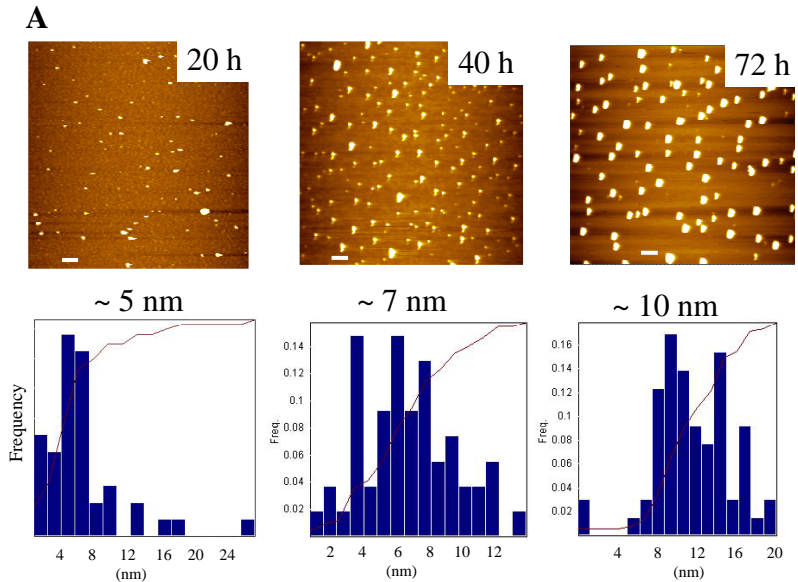

B

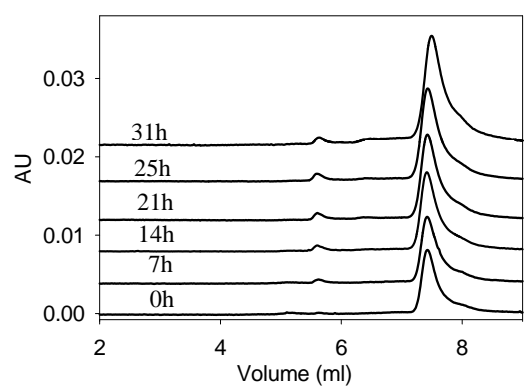

Fig. (2). (A). Time course of oligomerization and fibrillation of $\alpha$-Syn $(70 \mu \mathrm{M})$ incubated with DOPAC (100 $\mu \mathrm{M})$ in $20 \mathrm{mM} \mathrm{pH} 7.4$ phosphate buffer and $100 \mathrm{mM} \mathrm{NaCl}$ at $37^{\circ} \mathrm{C}$ as detected by AFM imaging. Scale bar is $200 \mathrm{~nm}$. The lower panels show the heights distribution and average heights are shown above the panels.

(B). Time course of changes in SEC HPLC profile of $\alpha$-Syn $(70 \mu \mathrm{M})$ incubated with DOPAC $(100 \mu \mathrm{M})$ at $\mathrm{pH} 7.4,37^{\circ} \mathrm{C}$ with agitation. 
DOPAC binding. Thus, oligomers "stabilized" by DOPAC can dissociate easily upon dilution (SDS-PAGE also showed only monomeric $\alpha$-Syn, data not shown). This behavior is similar to that of transient oligomers formed during the incubation of $\alpha$-Syn alone. However, in contrast to the case of incubation of $\alpha$-Syn alone, the oligomers "stabilized" by DOPAC do not aggregate into fibrils [45].

Since $\alpha$-Syn is a natively unfolded protein, whose hydrodynamic dimensions dramatically exceed those of the globular protein of similar size $\left(R_{S}\right.$ of $31.8 \AA$ instead of $19.1 \AA$ expected for a globular protein with the molecular mass of $14,460 \mathrm{Da})$, it migrates on the SEC column as a protein with high apparent molecular mass $(\sim 60 \mathrm{kDa})$. Therefore, the calibration of SEC column would not provide any adequate information on the molecular masses of various species formed during the $\alpha$-Syn aggregation. However, SEC can be utilized to visualize the distribution of monomeric and oligomeric (if any) species. Therefore, in our experiments SEC was used only to show that the soluble oligomers transiently populated during the $\alpha$-synuclein fibrillation in the absence of DOPAC are not stable since they completely dissociate during the SEC experiments. On the other hand, the coincubation of $\alpha$-synuclein with DOPAC increased stability of these oligomers. DOPAC Does Not Induce Changes in the $\alpha$-Syn Secondary Structure.

To further characterize the effect of DOPAC on $\alpha$-Syn, the time course of changes in $\alpha$-Syn far-UV CD spectra induced by the prolonged incubation in the presence of DOPAC was analyzed. ATR-FTIR and far-UV CD spectroscopy were used to monitor potential time-dependent changes in the secondary structure of $\alpha$-Syn when incubated with DOPAC. Fig. 3A shows that the far-UV CD spectrum of fresh $\alpha$-Syn was typical for a polypeptide chain with a random coil structure, being characterized by a deep minimum at $\sim 200 \mathrm{~nm}$ and the lack of characteristic bands in the vicinity of $220 \mathrm{~nm}$. There was an oligomerization-induced decrease in the intensity of a peak at $200 \mathrm{~nm}$ during the first two days of incubation (Fig. 3A). However, co-incubation of $\alpha$-Syn with DOPAC did not induce peaks related to the ordered secondary structure elements, such as $\alpha$-helix and $\beta$-sheet. This implies that $\alpha$-Syn mostly retained its highly disordered structure, becoming slightly more "organized" after the coincubation with DOPAC. This conclusion was further supported by the ATR-FTIR analysis, which is being more sensitive to $\beta$-sheet failed to find noticeable structural changes in $\alpha$-Syn secondary structure before and after the incubation in the presence of DOPAC (Fig. 3B).

\section{DOPAC-Induced Decrease in the $\alpha$-Syn Binding to Lipid Membranes}

The characteristic property of $\alpha$-Syn related to its normal biological function is that this protein undergoes dramatic structural change from the "natively unfolded" conformation to a highly $\alpha$-helical form once it binds to the negatively charged lipids [28]. Therefore, at the next stage we tested the effect of DOPAC binding on the ability of $\alpha$-Syn to interact with lipid membranes. To this end, small unilamellar vesicles (SUVs) made from 1:1 PA:PC phospholipids were added to protein solutions after incubating $\alpha$-Syn with or without DOPAC at $37^{\circ} \mathrm{C}$ with no agitation for two days. The weight ratio of SUVs to $\alpha$-Syn in these experiments was
10:1. Fig. 4 shows that $\alpha$-Syn incubated alone possessed strong membrane binding capability as indicated by a dramatic increase in its $\alpha$-helical structure content. The protein incubated for two days with DOPAC showed significant less $\alpha$-helical structure compared to the protein incubated with no DOPAC (Fig. 4). This dramatic decrease in the efficiency of $\alpha$-Syn to interact with lipid vesicles can be due to the higher oligomerization tendency of a protein incubated in the presence of DOPAC. Alternatively, it can be due to the direct binding of DOPAC to $\alpha$-Syn, possibly to the $\mathrm{N}$-terminal region of a protein [45], which lessened the efficiency of $\alpha$ Syn interaction with lipids.
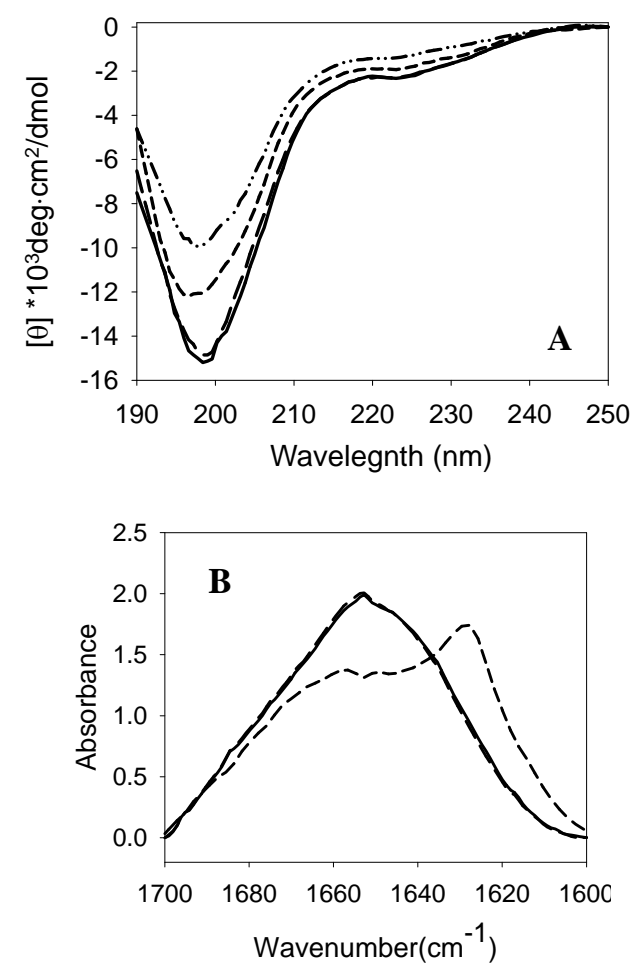

Fig. (3). (A). Far-UV CD spectra of fresh $\alpha$-Syn $(70 \mu \mathrm{M})$ alone (solid line) and $\alpha$-Syn with DOPAC $(100 \mu \mathrm{M})$ after 0 (long dash), 1 (short dash) or 2 (dash dot dot) days incubation at $\mathrm{pH} 7.4,37^{\circ} \mathrm{C}$ with no agitation.

(B). FTIR spectra of $\alpha$-Syn $(70 \mu \mathrm{M})$ with DOPAC $(100 \mu \mathrm{M})$ after 2 days incubation (long dash) or $\alpha$-Syn alone (solid) after 2 days incubation without agitation. Spectrum of fibrillar $\alpha$-Syn is shown for comparison (short dash). Spectra were area normalized.

\section{DISCUSSION}

Small oligomeric species are often found as precursors of amyloid fibrils. In several instances, the origination of these oligomers was attributed to a competition between amorphous and fibrillar aggregation [48-50]. Presently, the particular role of small oligomers in the process of amyloid fibril formation is unclear. However, recent years evidenced a significant increase in the interest of researchers to these molecular species as their presence was linked to the neurodegenerative processes. There are several potential mechanisms by which these oligomeric species exhibit their toxic effects [51]. For example, interactions of some of these oligomers with specific receptors dysregulates the receptors' functions leading to the impairment or activation of bio- 
chemical pathways [52]. Interaction of oligomers with membranes was shown to lead to the modification of properties of membrane themselves [53]. Furthermore, oligomeric species can also create channels in the membranes.

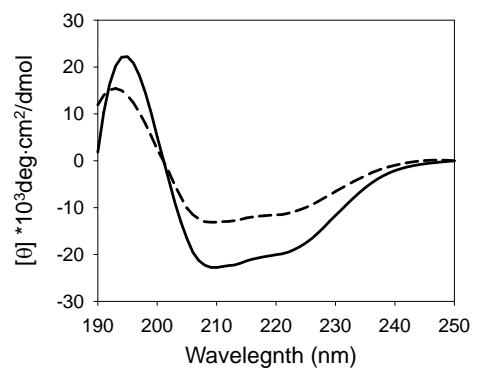

Fig. (4). Far-UV CD spectra of $\alpha$-Syn $(70 \mu \mathrm{M})$ in the presence of small unilamellar vesicles $(1: 1 \mathrm{PA}: \mathrm{PC})$ at $1: 10$ (protein to lipids) mass ratio: $\alpha$-Syn after 2 days incubation at $\mathrm{pH} 7.4,37^{\circ} \mathrm{C}$ without agitation with DOPAC $(100 \mu \mathrm{M})$ (dash line) or alone (solid line).

Our current and previous data show that DOPAC stabilizes transient $\alpha$-Syn oligomers [45]. In fact, our data suggest that at low DOPAC concentrations, where the molar ratios of $\alpha$-Syn to DOPAC exceed unity, the elongation time for $\alpha$-Syn fibrillation increases with the increase in the DOPAC concentration. There are several potential mechanisms for such DOPAC-induced inhibition of $\alpha$-Syn fibrillation. In one model, the DOPAC binding to $\alpha$-Syn stabilizes specific oligomers that morphologically are similar to the oligomers transiently populated during the $\alpha$-Syn incubation alone. Such transient oligomers can serve as normal "oligomer unit" of $\alpha$-Syn fibrils. We suggest that the inter-oligomeric interface of the DOPAC-stabilized oligomers can be different from that of the transient oligomers, preventing them from growing into the fibrils. Another possibility is that DOPAC can bind to the existing fibrils and block their elongation. In other words, the presence of DOPAC stabilizes some species, such as oligomers and proto-fibrils, and prevents fibril formation (Fig. 5).

Intermediates formed during the $\alpha$-Syn fibrillation have been proposed to be more toxic to dopaminergic neurons than the mature fibrils [54-58]. Although the toxicities of all these species (various oligomers, protofibrils and fibrils with various morphologies) are still under the debate, it is clear that DOPAC binding increases the diversity of aggregated $\alpha$ Syn species.

It is possible that binding of DOPAC to $\alpha$-Syn stabilizes some toxic intermediates during the protein fibrillation. It is well established that $\alpha$-Syn is able to adopt $\alpha$-helical structure on binding to negatively charged lipids. This structural transformation may be related to its normal function. We observed that DOPAC-induced oligomers of $\alpha$-Syn show less helicity in the presence of vesicles than the un-modified protein. This suggests that the formation of the DOPACstabilized oligomers leads to reduction in $\alpha$-synuclein capability to bind lipids. Furthermore, DOPAC bound $\alpha$-Syn binds to negatively charged lipid less strongly than the intact protein, this indicates DOPAC binding might impair the normal function of $\alpha$-Syn.

In summary, at physiologically relevant concentrations, DOPAC binds to $\alpha$-Syn and results in the formation of specific $\alpha$-Syn oligomers, which do not form fibrils and possess decreased membrane binding capabilities. Therefore, DOPAC and other dopamine derivatives, might lead to gainof-toxicity of $\alpha$-Syn aggregates and loss-of-function of $\alpha$ Syn, both of which could be related to progression of PD.

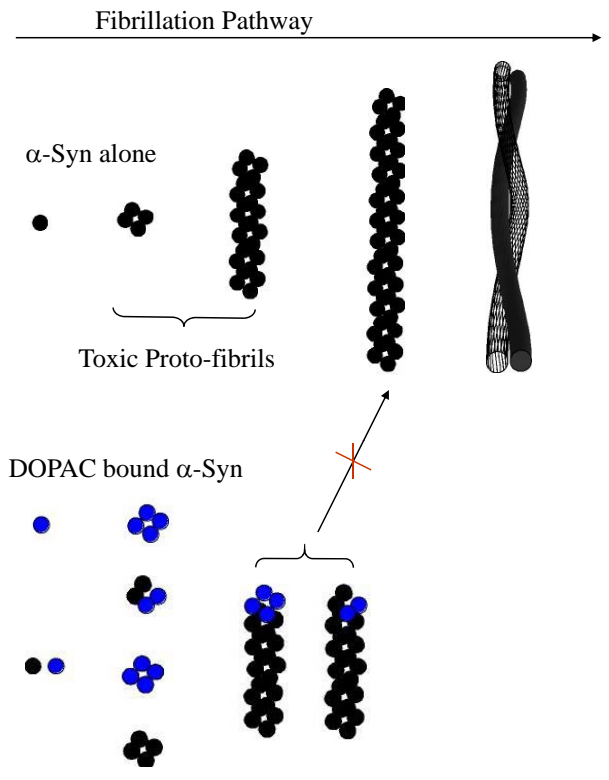

Fig. (5). Model of $\alpha$-Syn oligomerization and fibrillation in the absence or presence of DOPAC. DOPAC might stabilize various intermediate species on the fibrillation pathway and prevent them from subsequent fibril formation. Note: DOPAC-bound species also possess decreased affinity to lipid membranes.

\begin{tabular}{|c|c|c|}
\hline \multicolumn{3}{|c|}{ ABBREVIATIONS } \\
\hline AFM & $=$ & Atomic Force Microscopy \\
\hline$\alpha-\operatorname{Syn}$ & $=$ & $\alpha$-Synuclein \\
\hline ATR-FTIR & $=$ & $\begin{array}{l}\text { Attenuated Total Reflectance } \\
\text { Transform Infrared }\end{array}$ \\
\hline $\mathrm{CD}$ & $=$ & Circular dichroism \\
\hline DOPAC & $=$ & 3, 4-dihydroxyphenyl acetic acid \\
\hline IR & $=$ & Infra red \\
\hline PA & $=$ & 1,2-dipalmitoyl-sn-glycero-3-phosphate \\
\hline $\mathrm{PC}$ & $=$ & $\begin{array}{l}\text { 1,2-dipalmitoyl-sn-glycero-3- } \\
\text { phosphocholine }\end{array}$ \\
\hline PD & $=$ & Parkinson's disease \\
\hline SEC & $=$ & Size-exclusion chromatography \\
\hline SDS-PAGE & $=$ & $\begin{array}{l}\text { Sodium dodecyl sulfate polyacryl- amide } \\
\text { gel electrophoresis }\end{array}$ \\
\hline SUV & $=$ & small unilamellar vesicle \\
\hline UV & $=$ & Ultra Violet \\
\hline
\end{tabular}

\section{ACKNOWLEDGEMENTS}

This research was supported in part by grants R01 NS39985 (A.L.F.), R01 LM007688-01A1 (V.N.U.) and GM071714-01A2 (V.N.U.) from the National Institutes of Health, and from the Program of Russian Academy of 
Sciences "Molecular and Cellular Biology" (V.N.U.). We gratefully acknowledge the support of the IUPUI Signature Centers Initiative.

\section{REFERENCES}

[1] Baba, M.; Nakajo, S.; Tu, P. H.; Tomita, T.; Nakaya, K.; Lee, V. M.; Trojanowski, J. Q.; Iwatsubo, T., Aggregation of alphasynuclein in Lewy bodies of sporadic Parkinson's disease and dementia with Lewy bodies. Am. J. Pathol., 1998, 152 (4), 879-84.

[2] Dunnett, S. B.; Bjorklund, A. Prospects for new restorative and neuroprotective treatments in Parkinson's disease. Nature, 1999, 399 (6738 Suppl), A32-A39.

[3] Spillantini, M. G.; Schmidt, M. L.; Lee, V. M.; Trojanowski, J. Q.; Jakes, R.; Goedert, M. Alpha-synuclein in Lewy bodies. Nature, 1997, 388 (6645), 839-40.

[4] Uversky, V. N. Neuropathology, biochemistry, and biophysics of alpha-synuclein aggregation. J. Neurochem., 2007, 103 (1), 17-37.

[5] Galpern, W. R.; Lang, A. E. Interface between tauopathies and synucleinopathies: a tale of two proteins. Ann. Neurol., 2006, 59 (3), 449-58.

[6] Norris, E. H.; Giasson, B. I.; Lee, V. M. Alpha-synuclein: normal function and role in neurodegenerative diseases. Curr. Top. Dev. Biol., 2004, 60, 17-54.

[7] Marti, M. J.; Tolosa, E.; Campdelacreu, J. Clinical overview of the synucleinopathies. Mov. Disord., 2003, 18 (Suppl 6), S21-27.

[8] Goedert, M. Parkinson's disease and other alpha-synucleinopathies. Clin. Chem. Lab. Med., 2001, 39 (4), 308-12.

[9] Galvin, J. E.; Lee, V. M.; Trojanowski, J. Q. Synucleinopathies: clinical and pathological implications. Arch. Neurol., 2001, 58 (2), 186-90.

[10] Spillantini, M. G.; Goedert, M. The alpha-synucleinopathies: Parkinson's disease, dementia with Lewy bodies, and multiple system atrophy. Ann. N Y Acad. Sci., 2000, 920, 16-27.

[11] Goedert, M. Filamentous nerve cell inclusions in neurodegenerative diseases: tauopathies and alpha-synucleinopathies. Philos. Trans. R Soc. Lond. B Biol. Sci., 1999, 354 (1386), 1101-18.

[12] Spillantini, M. G.; Crowther, R. A.; Jakes, R.; Cairns, N. J.; Lantos, P. L.; Goedert, M. Filamentous alpha-synuclein inclusions link multiple system atrophy with Parkinson's disease and dementia with Lewy bodies. Neurosci. Lett., 1998, 251 (3), 205-8.

[13] Uversky, V. N. Alpha-synuclein misfolding and neurodegenerative diseases. Curr. Protein Pept. Sci., 2008, 9 (5), 507-40.

[14] Uversky, V. N.; Eliezer, D. Biophysics of Parkinson's disease: structure and aggregation of alpha-synuclein. Curr. Protein Pept. Sci., 2009, 10 (5), 483-99.

[15] Dev, K. K.; Hofele, K.; Barbieri, S.; Buchman, V. L.; van der Putten, H. Part II: alpha-synuclein and its molecular pathophysiological role in neurodegenerative disease. Neuropharmacology, 2003, 45 (1), 14-44.

[16] Crowther, R. A.; Jakes, R.; Spillantini, M. G.; Goedert, M. Synthetic filaments assembled from C-terminally truncated alphasynuclein. FEBS Lett., 1998, 436 (3), 309-12.

[17] Crowther, R. A.; Daniel, S. E.; Goedert, M. Characterisation of isolated alpha-synuclein filaments from substantia nigra of Parkinson's disease brain. Neurosci. Lett., 2000, 292 (2), 128-30.

[18] El-Agnaf, O. M.; Jakes, R.; Curran, M. D.; Wallace, A. Effects of the mutations Ala30 to Pro and Ala53 to Thr on the physical and morphological properties of alpha-synuclein protein implicated in Parkinson's disease. FEBS Lett., 1998, 440 (1-2), 67-70.

[19] Conway, K. A.; Harper, J. D.; Lansbury, P. T. Accelerated in vitro fibril formation by a mutant alpha-synuclein linked to early-onset Parkinson disease. Nat. Med., 1998, 4 (11), 1318-20.

[20] Weinreb, P. H.; Zhen, W.; Poon, A. W.; Conway, K. A.; Lansbury, P. T., Jr. NACP, a protein implicated in Alzheimer's disease and learning, is natively unfolded. Biochemistry, 1996, 35 (43), 13709715 .

[21] Bussell, R., Jr.; Eliezer, D. Residual structure and dynamics in Parkinson's disease-associated mutants of alpha-synuclein. J. Biol. Chem., 2001, 276 (49), 45996-46003.

[22] Eliezer, D.; Kutluay, E.; Bussell, R., Jr.; Browne, G. Conformational properties of alpha-synuclein in its free and lipid-associated states. J. Mol. Biol., 2001, 307 (4), 1061-73.

[23] Uversky, V. N.; Li, J.; Fink, A. L. Evidence for a partially folded intermediate in alpha-synuclein fibril formation. J. Biol. Chem., 2001, $276(14), 10737-44$.
[24] Li, J.; Uversky, V. N.; Fink, A. L. Effect of familial Parkinson's disease point mutations $\mathrm{A} 30 \mathrm{P}$ and $\mathrm{A} 53 \mathrm{~T}$ on the structural properties, aggregation, and fibrillation of human alpha-synuclein. Biochemistry, 2001, 40 (38), 11604-613.

[25] Uversky, V. N. A protein-chameleon: conformational plasticity of alpha-synuclein, a disordered protein involved in neurodegenerative disorders. J Biomol. Struct. Dyn., 2003, 21 (2), 211-34.

[26] Clayton, D. F.; George, J. M. The synucleins: a family of proteins involved in synaptic function, plasticity, neurodegeneration and disease. Trends Neurosci., 1998, 21 (6), 249-54.

[27] Uversky, V. N.; Fink, A. L. Amino acid determinants of alphasynuclein aggregation: putting together pieces of the puzzle. FEBS Lett., 2002, 522 (1-3), 9-13.

[28] Davidson, W. S.; Jonas, A.; Clayton, D. F.; George, J. M. Stabilization of alpha-synuclein secondary structure upon binding to synthetic membranes. J. Biol. Chem., 1998, 273 (16), 9443-49.

[29] Perrin, R. J.; Woods, W. S.; Clayton, D. F.; George, J. M. Interaction of human alpha-Synuclein and Parkinson's disease variants with phospholipids. Structural analysis using site-directed mutagenesis. J. Biol. Chem., 2000, 275 (44), 34393-8.

[30] Zhu, M.; Fink, A. L. Lipid binding inhibits alpha-synuclein fibril formation. J. Biol. Chem., 2003, 278 (19), 16873-7.

[31] Jao, C. C.; Der-Sarkissian, A.; Chen, J.; Langen, R. Structure of membrane-bound alpha-synuclein studied by site-directed spin labeling. Proc. Natl. Acad. Sci. U.S.A., 2004, 101 (22), 8331-6.

[32] Bisaglia, M.; Schievano, E.; Caporale, A.; Peggion, E.; Mammi, S. The 11-mer repeats of human alpha-synuclein in vesicle interactions and lipid composition discrimination: a cooperative role. Biopolymers, 2006, 84 (3), 310-16.

[33] Lotharius, J.; Brundin, P. Pathogenesis of Parkinson's disease: dopamine, vesicles and alpha-synuclein. Nat. Rev. Neurosci., 2002, 3 (12), 932-42.

[34] Lotharius, J.; Brundin, P. Impaired dopamine storage resulting from alpha-synuclein mutations may contribute to the pathogenesis of Parkinson's disease. Hum. Mol. Genet., 2002, 11 (20), 23952407.

[35] Lotharius, J.; Barg, S.; Wiekop, P.; Lundberg, C.; Raymon, H. K.; Brundin, P. Effect of mutant alpha-synuclein on dopamine homeostasis in a new human mesencephalic cell line. J. Biol. Chem., 2002, 277 (41), 38884-94.

[36] Tao-Cheng, J. H. Activity-related redistribution of presynaptic proteins at the active zone. Neuroscience, 2006, 141 (3), 1217-24.

[37] Fortin, D. L.; Nemani, V. M.; Voglmaier, S. M.; Anthony, M. D.; Ryan, T. A.; Edwards, R. H. Neural activity controls the synaptic accumulation of alpha-synuclein. J. Neurosci., 2005, 25 (47), 10913-21.

[38] Conway, K. A.; Rochet, J. C.; Bieganski, R. M.; Lansbury, P. T., Jr. Kinetic stabilization of the alpha-synuclein protofibril by a dopamine-alpha-synuclein adduct. Science, 2001, 294 (5545), 1346-9.

[39] Norris, E. H.; Giasson, B. I.; Hodara, R.; Xu, S.; Trojanowski, J. Q.; Ischiropoulos, H.; Lee, V. M. Reversible inhibition of alphasynuclein fibrillization by dopaminochrome-mediated conformational alterations. J. Biol. Chem., 2005, 280 (22), 21212-19.

[40] Li, J.; Zhu, M.; Manning-Bog, A. B.; Di Monte, D. A.; Fink, A. L. Dopamine and L-dopa disaggregate amyloid fibrils: implications for Parkinson's and Alzheimer's disease. FASEB. J., 2004, 18 (9), 962-4.

[41] Zhu, M.; Rajamani, S.; Kaylor, J.; Han, S.; Zhou, F.; Fink, A. L. The flavonoid baicalein inhibits fibrillation of alpha-synuclein and disaggregates existing fibrils. J. Biol. Chem., 2004, 279 (26), 26846-57.

[42] Li, J.; Zhu, M.; Rajamani, S.; Uversky, V. N.; Fink, A. L. Rifampicin inhibits alpha-synuclein fibrillation and disaggregates fibrils. Chem. Biol., 2004, 11 (11), 1513-21.

[43] Hong, D. P.; Fink, A. L.; Uversky, V. N. Structural characteristics of alpha-synuclein oligomers stabilized by the flavonoid baicalein. J. Mol. Biol., 2008, 383 (1), 214-23.

[44] Xu, J.; Kao, S. Y.; Lee, F. J.; Song, W.; Jin, L. W.; Yankner, B. A. Dopamine-dependent neurotoxicity of alpha-synuclein: a mechanism for selective neurodegeneration in Parkinson disease. Nat. Med., 2002, 8 (6), 600-06.

[45] Zhou, W.; Gallagher, A.; Hong, D. P.; Long, C.; Fink, A. L.; Uversky, V. N. At low concentrations, 3,4-dihydroxyphenylacetic acid (DOPAC) binds non-covalently to alpha-synuclein and prevents its fibrillation. J. Mol. Biol., 2009, 388 (3), 597-610. 
[46] Goers, J.; Uversky, V. N.; Fink, A. L. Polycation-induced oligomerization and accelerated fibrillation of human alpha-synuclein in vitro. Protein Sci., 2003, 12 (4), 702-7.

[47] Oberg, K. A.; Fink, A. L. A new attenuated total reflectance Fourier transform infrared spectroscopy method for the study of proteins in solution. Anal. Biochem., 1998, 256 (1), 92-106.

[48] Dobson, C. M. Protein folding and misfolding. Nature, 2003, 426 (6968), 884-90.

[49] Caughey, B.; Lansbury, P. T. Protofibrils, pores, fibrils, and neurodegeneration: separating the responsible protein aggregates from the innocent bystanders. Annu. Rev. Neurosci., 2003, 26, 267-98.

[50] Haass, C.; Selkoe, D. J. Soluble protein oligomers in neurodegeneration: lessons from the Alzheimer's amyloid beta-peptide. Nat. Rev. Mol. Cell. Biol., 2007, 8 (2), 101-12.

[51] Bucciantini, M.; Giannoni, E.; Chiti, F.; Baroni, F.; Formigli, L.; Zurdo, J.; Taddei, N.; Ramponi, G.; Dobson, C. M.; Stefani, M. Inherent toxicity of aggregates implies a common mechanism for protein misfolding diseases. Nature, 2002, 416 (6880), 507-11.

[52] Rubinsztein, D. C. The roles of intracellular protein-degradation pathways in neurodegeneration. Nature, 2006, 443 (7113), 780-6.

[53] Diaz, J. C.; Simakova, O.; Jacobson, K. A.; Arispe, N.; Pollard, H. B. Small molecule blockers of the Alzheimer Abeta calcium chan- nel potently protect neurons from Abeta cytotoxicity. Proc. Natl. Acad. Sci. U.S.A., 2009, 106 (9), 3348-53.

[54] Conway, K. A.; Lee, S. J.; Rochet, J. C.; Ding, T. T.; Williamson, R. E.; Lansbury, P. T., Jr. Acceleration of oligomerization, not fibrillization, is a shared property of both alpha-synuclein mutations linked to early-onset Parkinson's disease: implications for pathogenesis and therapy. Proc. Natl. Acad. Sci. USA, 2000, 97 (2), 5716.

[55] Tompkins, M. M.; Basgall, E. J.; Zamrini, E.; Hill, W. D. Apoptotic-like changes in Lewy-body-associated disorders and normal aging in substantia nigral neurons. Am. J. Pathol., 1997, 150 (1), 119-31.

[56] Tompkins, M. M.; Hill, W. D. Contribution of somal Lewy bodies to neuronal death. Brain Res., 1997, 775 (1-2), 24-29.

[57] Masliah, E.; Rockenstein, E.; Veinbergs, I.; Mallory, M.; Hashimoto, M.; Takeda, A.; Sagara, Y.; Sisk, A.; Mucke, L. Dopaminergic loss and inclusion body formation in alpha-synuclein mice: implications for neurodegenerative disorders. Science, 2000, 287 (5456), 1265-9.

[58] Goldberg, M. S.; Lansbury, P. T., Jr. Is there a cause-and-effect relationship between alpha-synuclein fibrillization and Parkinson's disease? Nat. Cell Biol., 2000, 2 (7), E115-119. 